\title{
APLIKASI BIMBINGAN SKRIPSI STUDI KASUS FAKULTAS TEKNOLOGI INFORMASI UNISKA UNTUK KEEFEKTIVITAS WAKTU SELESAI MASA BIMBINGAN
}

\author{
Zaenuddin, M.Kom ${ }^{1)}$, Galih Mahalisa, M. Kom ${ }^{2)}$ \\ ${ }^{\mathbf{1}}$ Fakultas Teknologi Informasi, Universitas Islam Kalimantan Muhammad Arsyad Al Banjari Banjarmasin \\ email : galih.mahalisa@gmail.com \\ ${ }^{2}$ Fakultas Teknologi Informasi, Universitas Islam Kalimantan Muhammad Arsyad Al Banjari Banjarmasin \\ email : zaenuddin.uniska@gmail.com
}

\begin{abstract}
ABSTRAK
Aplikasi adalah suatu program komputer yang dibuat untuk mengerjakan dan melaksanakan tugas khusus dari pengguna khususnya pada studi kasus yang ada pada Fakultas Teknologi Informasi UNISKA. Perlunya sebuah aplikasi bantuan untuk mengatasi efisiensi waktu pada saat bimbingan skripsi bisa dilihat dari hasil obsevasi yaitu sebanyak $82 \%$ dari 20 responden kurang puas dengan metode konvensional yang digunakan saat ini terutama masalah efektivitas masa bimbingan. Hasil yang didapatkan berdasarkan analisa dari implementasi dan pengujian menggunakan metode Standart ISO 9126 pada aplikasi tersebut maka didapatkan sebanyak 131 sample yang terdiri dari 18 dosen, 120 mahasiswa, dan lorang staf FTI, salah satu pengujian dengan hasil dari pengujian functionality menyatakan 93\% termasuk skor baik, pengujian usability menyatakan $83 \%$ termasuk baik. Maka dari itu hasil observasi setelah menggunakan aplikasi dilakukan perhitungan ulang dari 20 responden presentase $90 \%$ menyatakan respon yang bagus untuk bisa menggunakan aplikasi ini sebagai alat pendamping dalam melakukan konsultasi skripsi secara online.
\end{abstract}

Kata Kunci : aplikasi, skripsi, efisiensi, waktu, efektivitas, konsultasi, online

\section{PENDAHULUAN}

Skripsi adalah istilah yang digunakan di Indonesia untuk mengilustrasikan suatu karya tulis ilmiah berupa paparan tulisan hasil penelitian sarjana S1 yang membahas suatu permasalahan/fenomena dalam bidang ilmu tertentu dengan menggunakan kaidah-kaidah yang berlaku. Waktu adalah hal yang dalam pelaksanaan bimbingan sangat berpengaruh, dengan kefektifan waktu akan berimbas pada masa bimbingan agar tidak terlalu ,lama dalam menyelasaikan laporan skripsi. Agar gelar sarjana S1 terpenuhi, diharuskan mahasiswa semester akhir untuk menyelesaikan skripsi. Pada umumnya mahasiswa akan membuat sebuah pengajuan proposal judul skripsi, jika proposal telah lolos oleh tim reviewer maka judul tersebut bisa dilanjutkan sebagai laporan skripsi.
Sistem yang digunakan sekarang pada sebagian besar universitas adalah masih menggunakan media print out atau cetakan kertas dengan beberapa eksemplar untuk mengajukan proposal skripsi ataupun melakukan bimbingan dengan dosen pembimbing. Seharusnya hal tersebut bisa lebih efisien jika dilakukan secara online, meminimalisir print out kertas yang terbuang, jadi jika proposal sudah fix setelah revisi dari dosen, barulah membuat print out untuk proposal ataupun laporan skripsi.

Maka dari itu perlunya suatu sistem yang mengelola dalam pengajuan judul, proposal hingga laporan skripsi dengan sebuah sistem berbasis online agar lebih efisiensi penggunaan kertas. 


\section{METODE PENELITIAN}

Penelitian ini menggunakan istilah Research and Development adalah metode yang digunakan untuk menghasilkan produk tertentu dan menguji daripada keefektifan produk tersebut bagi pengguna. Pendekatan model perangkat lunak untuk mendukung penelitian ini menggunakan model waterfall, yang melalui beberapa tahapan, yaitu seperti pada gambar dibawah ini:

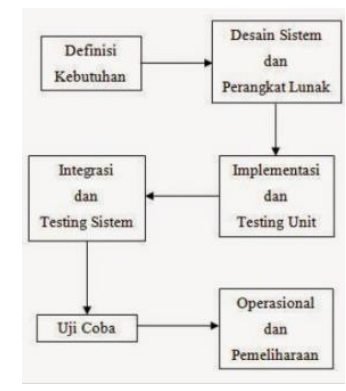

Gambar 1 Model Waterfall

1. Tahap analisis kebutuhan

Pada tahap ini tim melakukan survey dengan mengambil sample sebanyak 20 orang responden, tujuannya agar mengetahui presentase kepuasan responden sebelum menggunakan aplikasi tersebut.

2. Tahap desain sistem dan perangkat lunak Pada tahap ini didesain dengan menggunakan diagram konteks sebagai awal alur dari sebuah sistem/aplikasi. Untuk perancangan desain antarmuka menggunakan tools Balsamic Mockup.

3. Tahap implementasi dan testing unit

Tahap ini lebih menjelaskan hasil dari desain dan perancangan antar muka sistem yang sudah dalam bentuk website dan menggunakan framework PHP (Laravel) dengan basis data mysql

4. Tahap integrasi dan testing sistem

Integrasi dalam tahap ini adalah pengelolaan database agar bisa support dengan framework yang dibuat pada implementasi

5. Tahap pengujian

Tahap pengujian menggunakan metode Standart ISO 9126 yang terdiri dari aspek aspek functionality, security, usability, efficiency, maintainability, dan portability

6. Tahap pemeliharaan

Tahap ini adalah bagian pemeliharan antara aplikasi dengan user pengguna

\section{HASIL DAN PEMBAHASAN}

a. Analisis Kebutuhan

Hasil dari 20 responden yaitu sebagai berikut :

Tabel 1 Kuisioner Analisa Kebutuhan

\begin{tabular}{|c|c|c|}
\hline Variabel & $\begin{array}{l}\text { Jumlah } \\
\text { Respon }\end{array}$ & Presentase \\
\hline $\begin{array}{l}\text { Kurang setuju } \\
\text { tentang sistem } \\
\text { konvensional } \\
\text { dalam konsultasi } \\
\text { skripsi? }\end{array}$ & $\begin{array}{c}17 \\
\text { orang }\end{array}$ & $85 \%$ \\
\hline $\begin{array}{lr}\text { Kurang puas } \\
\text { dengan sistem } \\
\text { konvensional } \\
\text { dalam konsultasi } \\
\text { bimbingan skripsi }\end{array}$ & $\begin{array}{c}15 \\
\text { orang }\end{array}$ & $75 \%$ \\
\hline $\begin{array}{l}\text { Tidak harus } \\
\text { menghilangkan } \\
\text { sistem } \\
\text { konvensional } \\
\text { dalam konsultasi } \\
\text { bimbingan skripsi } \\
\text { harus }\end{array}$ & $\begin{array}{c}19 \\
\text { orang }\end{array}$ & $95 \%$ \\
\hline $\begin{array}{l}\text { Sangat perlu } \\
\text { suatu aplikasi } \\
\text { konsultasi } \\
\text { bimbingan skripsi } \\
\text { online }\end{array}$ & $\begin{array}{c}17 \\
\text { orang }\end{array}$ & $85 \%$ \\
\hline $\begin{array}{l}\text { sistem } \\
\text { konvensional } \\
\text { dalam konsultasi } \\
\text { bimbingan skripsi } \\
\text { harus didampingi } \\
\text { dengan aplikasi } \\
\text { konsultasi online }\end{array}$ & $\begin{array}{c}14 \\
\text { orang }\end{array}$ & $70 \%$ \\
\hline
\end{tabular}

Berdasarkan hasil diatas rata-rata presentase di atas adalah 82\% kurang setuju dan kurang puas dalam melakukan bimbingan dengan sistem konvensional. 
b. Tahap Desain

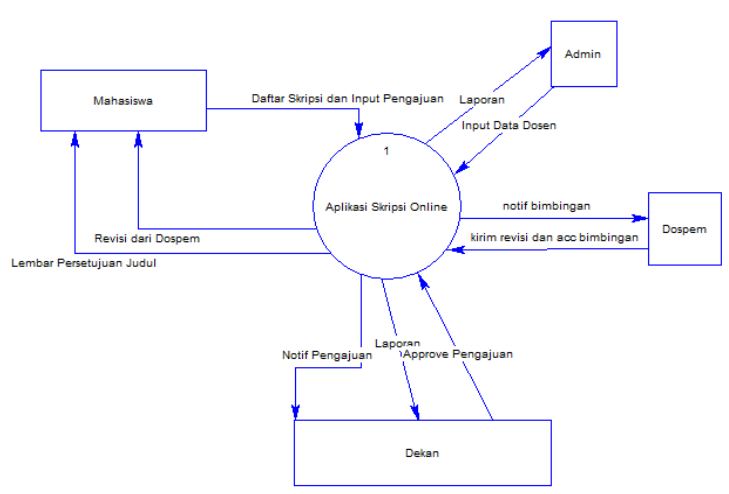

Gambar 2 Diagram Konteks

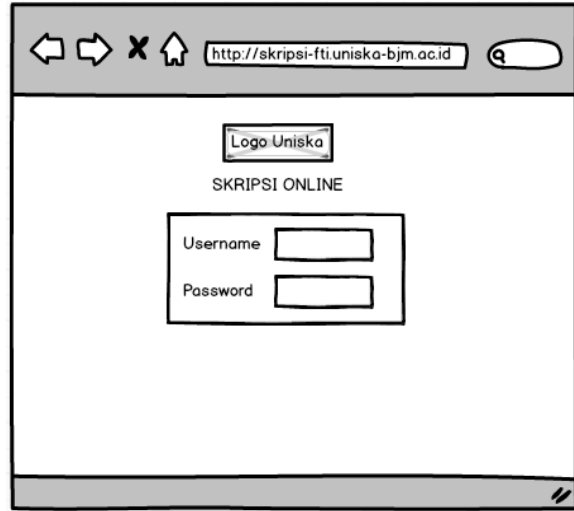

Gambar 3 Desain Mockup Login

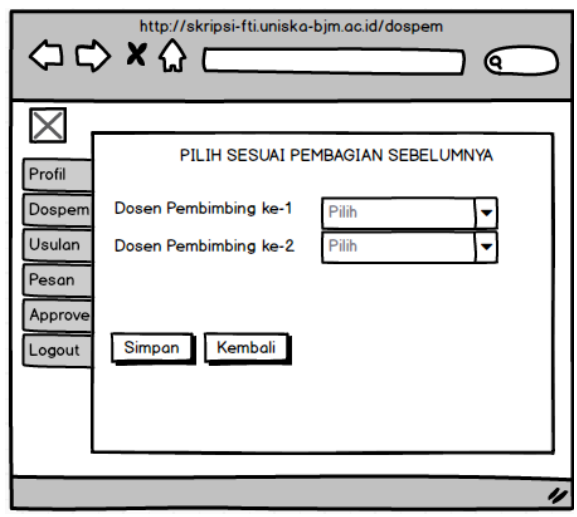

Gambar 4 Desain Mockup pembimbing c. Tahap Implementasi

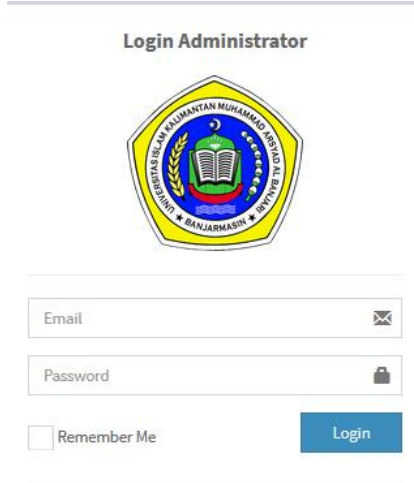

Register Akun baru

Gambar 5 Login Admin

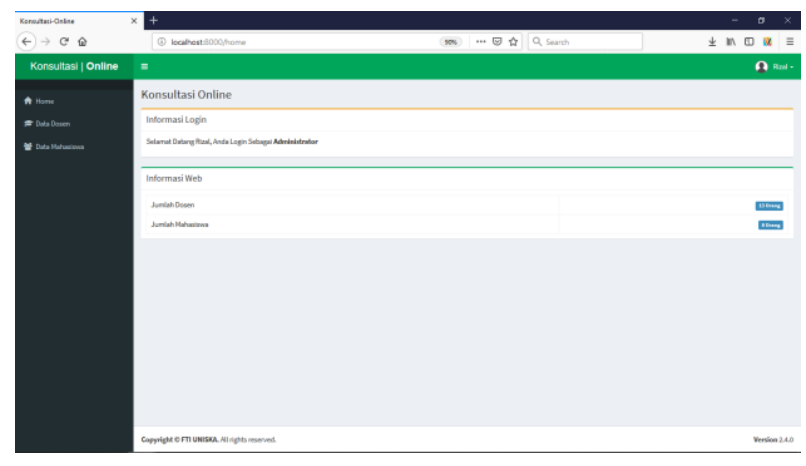

Gambar 6 Home Admin

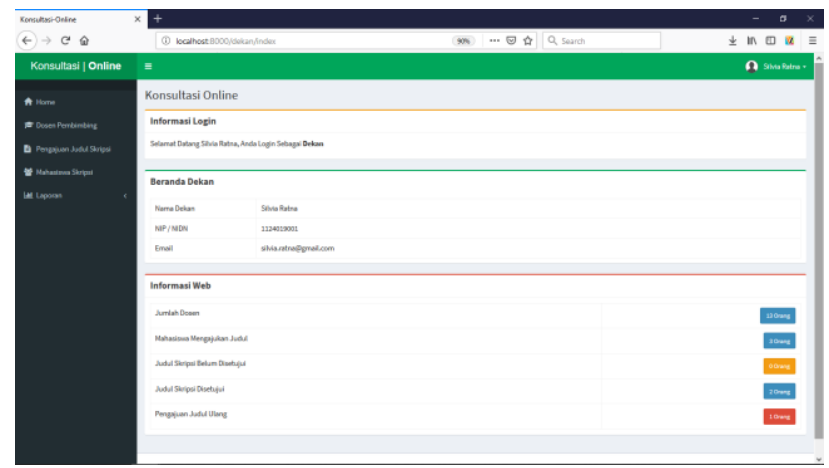

Gambar 7 Home Dekan

Jurnal Ilmiah “Technologia” 


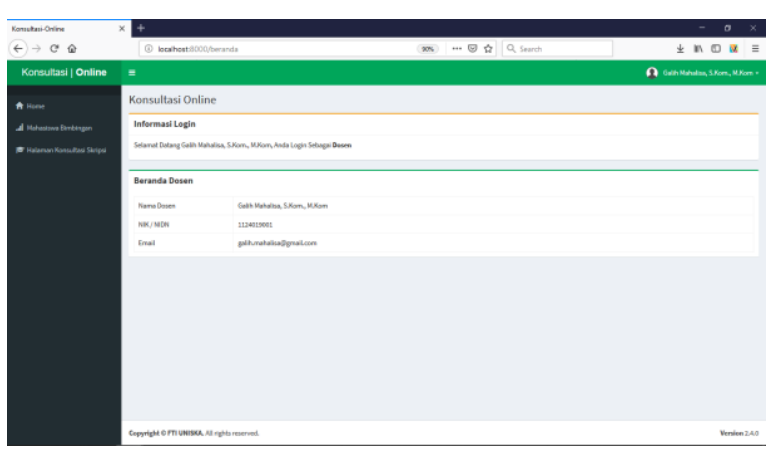

Gambar 8 Home Dosen

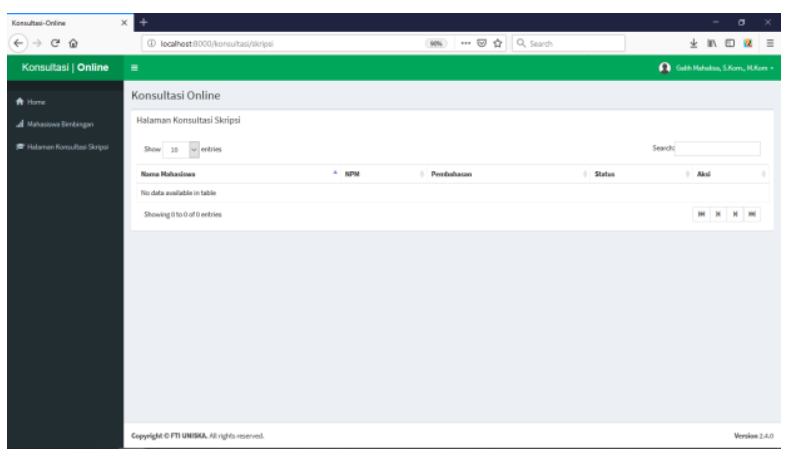

Gambar 9 Halaman Konsultasi

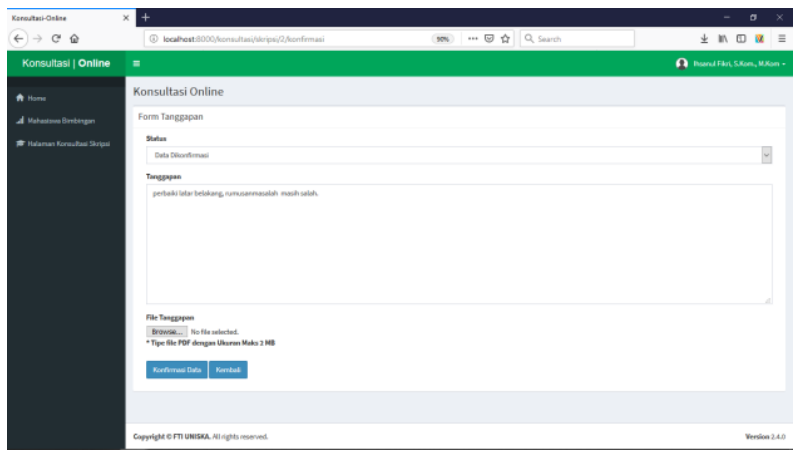

Gambar 10 Halaman bimbingan

\section{d. Tahap Pengujian}

Pada tahap ini pengujian dilakukan dengan mengundang Responden sebanyak 131 Orang yang terdiri dari 18 orang dosen, 112 orang mahasiswa, 1 orang staff FTI.
Tabel 2 Pengujian Functionality

\begin{tabular}{|c|c|c|c|}
\hline No & Pertanyaan & $\mathrm{Ya}$ & Tidak \\
\hline 1 & $\begin{array}{l}\text { Apakah fungsi } \\
\text { untuk mengakses } \\
\text { login admin sudah } \\
\text { berfungsi dengan } \\
\text { benar? }\end{array}$ & 131 & 0 \\
\hline 2 & $\begin{array}{l}\text { Apakah fungsi } \\
\text { untuk mengakses } \\
\text { halaman } \\
\text { pengunjung sudah } \\
\text { berfungsi dengan } \\
\text { benar? }\end{array}$ & 131 & 0 \\
\hline 3 & $\begin{array}{l}\text { Apakah halaman } \\
\text { menu utama pada } \\
\text { admin berfungsi } \\
\text { dengan benar? }\end{array}$ & 131 & 0 \\
\hline 4 & $\begin{array}{l}\text { Apakah halaman } \\
\text { menu utama pada } \\
\text { pengunjung } \\
\text { berfungsi dengan } \\
\text { benar? }\end{array}$ & 131 & 0 \\
\hline 5 & $\begin{array}{l}\text { Apakah menu } \\
\text { pencarian data } \\
\text { fakultas pada } \\
\text { halaman pengujung } \\
\text { berfungsi dengan } \\
\text { benar? }\end{array}$ & 131 & 0 \\
\hline 6 & $\begin{array}{l}\text { Apakah menu } \\
\text { pencarian data } \\
\text { dosen pada } \\
\text { halaman pengujung } \\
\text { berfungsi dengan } \\
\text { benar? }\end{array}$ & 131 & 0 \\
\hline 7 & $\begin{array}{l}\text { Apakah menu } \\
\text { pencarian data } \\
\text { ruangan pada } \\
\text { halaman pengujung } \\
\text { berfungsi dengan } \\
\text { benar? }\end{array}$ & 131 & 0 \\
\hline 8 & $\begin{array}{l}\text { Apakah menu } \\
\text { pencarian data } \\
\text { karyawan pada } \\
\text { halaman pengujung } \\
\text { berfungsi dengan } \\
\text { benar? }\end{array}$ & 131 & 0 \\
\hline 9 & $\begin{array}{l}\text { Apakah menu input } \\
\text { data fakultas pada } \\
\text { halaman admin } \\
\text { berfungsi dengan } \\
\text { benar? }\end{array}$ & 131 & 0 \\
\hline
\end{tabular}




\begin{tabular}{|c|c|c|c|}
\hline 10 & $\begin{array}{l}\text { Apakah menu input } \\
\text { data dosen pada } \\
\text { halaman admin } \\
\text { berfungsi dengan } \\
\text { benar? }\end{array}$ & 131 & 0 \\
\hline 11 & $\begin{array}{l}\text { Apakah menu input } \\
\text { data ruangan pada } \\
\text { halaman admin } \\
\text { berfungsi dengan } \\
\text { benar? }\end{array}$ & 131 & 0 \\
\hline 12 & $\begin{array}{l}\text { Apakah menu input } \\
\text { data karyawan pada } \\
\text { halaman admin } \\
\text { berfungsi dengan } \\
\text { benar? }\end{array}$ & 131 & 0 \\
\hline 13 & $\begin{array}{l}\text { Apakah menu cetak } \\
\text { data pada halaman } \\
\text { admin berfungsi } \\
\text { dengan benar? }\end{array}$ & 131 & 0 \\
\hline 14 & $\begin{array}{l}\text { Apakah hasil } \\
\text { pencarian ruangan } \\
\text { pada halaman } \\
\text { pengunjung } \\
\text { menampilkan } \\
\text { informasi dengan } \\
\text { benar? }\end{array}$ & 131 & 0 \\
\hline 15 & $\begin{array}{l}\text { Apakah hasil } \\
\text { pencarian dosen } \\
\text { pada halaman } \\
\text { pengunjung } \\
\text { menampilkan } \\
\text { informasi dengan } \\
\text { benar? }\end{array}$ & 131 & 0 \\
\hline 16 & $\begin{array}{l}\text { Apakah hasil } \\
\text { pencarian Fakultas } \\
\text { pada halaman } \\
\text { pengunjung } \\
\text { menampilkan } \\
\text { informasi dengan } \\
\text { benar? }\end{array}$ & 131 & 0 \\
\hline 17 & $\begin{array}{l}\text { Apakah hasil } \\
\text { pencarian karyawan } \\
\text { pada halaman } \\
\text { pengunjung } \\
\text { menampilkan } \\
\text { informasi dengan } \\
\text { benar? }\end{array}$ & 131 & 0 \\
\hline 18 & $\begin{array}{l}\text { Apakah } \\
\text { penginputan data } \\
\text { fakultas pada } \\
\text { halaman admin } \\
\text { berfungsi dengan }\end{array}$ & 131 & 0 \\
\hline
\end{tabular}

\begin{tabular}{|c|c|c|c|}
\hline & benar? & & \\
\hline 19 & $\begin{array}{l}\text { Apakah } \\
\text { penginputan data } \\
\text { dosen pada } \\
\text { halaman admin } \\
\text { berfungsi dengan } \\
\text { benar? }\end{array}$ & 131 & 0 \\
\hline 20 & $\begin{array}{l}\text { Apakah } \\
\text { penginputan data } \\
\text { ruangan pada } \\
\text { halaman admin } \\
\text { berfungsi dengan } \\
\text { benar? }\end{array}$ & 131 & 0 \\
\hline 21 & $\begin{array}{l}\text { Apakah } \\
\text { penginputan data } \\
\text { karyawan pada } \\
\text { halaman admin } \\
\text { berfungsi dengan } \\
\text { benar? }\end{array}$ & 131 & 0 \\
\hline 22 & $\begin{array}{l}\text { Apakah cetak data } \\
\text { pengunjung pada } \\
\text { halaman admin } \\
\text { berfungsi dengan } \\
\text { benar? }\end{array}$ & 131 & 0 \\
\hline 23 & $\begin{array}{l}\text { Apakah informasi } \\
\text { Statistik pengujung } \\
\text { berfungsi dengan } \\
\text { benar? }\end{array}$ & 131 & 0 \\
\hline 24 & $\begin{array}{l}\text { Apakah halaman } \\
\text { kontak berfungsi } \\
\text { informasi dengan } \\
\text { benar? }\end{array}$ & 131 & 0 \\
\hline \multirow[t]{2}{*}{25} & $\begin{array}{l}\text { Apakah halaman } \\
\text { link berfungsi } \\
\text { informasi dengan } \\
\text { benar? }\end{array}$ & 131 & 0 \\
\hline & Total & 331 & 44 \\
\hline
\end{tabular}

Dari hasil diatas dapat diketahui persentase untuk masing-masing penilaian, yaitu

$\begin{array}{lllr}\text { Ya } & 0,9333333 & \times 100 \% & 93 \% \\ \text { Tidak } & 0,0666667 & \times 100 \% & 7 \%\end{array}$


Analisis Data Pengujian Functionality

\begin{tabular}{|c|c|c|}
\hline $\begin{array}{l}\text { Perta } \\
\text { nyaa } \\
\text { n }\end{array}$ & $\begin{array}{l}\text { Skor } \\
\text { Total }\end{array}$ & Skor Maksimum \\
\hline 1 & 131 & 131 \\
\hline 2 & 131 & 131 \\
\hline 3 & 131 & 131 \\
\hline 4 & 131 & 131 \\
\hline 5 & 131 & 131 \\
\hline 6 & 131 & 131 \\
\hline 7 & 131 & 131 \\
\hline 8 & 131 & 131 \\
\hline 9 & 131 & 131 \\
\hline 10 & 131 & 131 \\
\hline 11 & 131 & 131 \\
\hline 12 & 131 & 131 \\
\hline 13 & 131 & 131 \\
\hline 14 & 131 & 131 \\
\hline 15 & 131 & 131 \\
\hline 16 & 131 & 131 \\
\hline 17 & 131 & 131 \\
\hline 18 & 131 & 131 \\
\hline 19 & 131 & 131 \\
\hline 20 & 131 & 131 \\
\hline 21 & 131 & 131 \\
\hline 22 & 131 & 131 \\
\hline 23 & 131 & 131 \\
\hline 24 & 131 & 131 \\
\hline 25 & 131 & 131 \\
\hline 26 & 131 & 131 \\
\hline 27 & 131 & 131 \\
\hline 28 & 0 & 131 \\
\hline 29 & 0 & 131 \\
\hline \multirow[t]{2}{*}{30} & 131 & 131 \\
\hline & 3668 & 3930 \\
\hline
\end{tabular}

Berdasarkan analisa diatas maka didapatkan seperti yang dibawah ini :

$$
0,933333333 \times 100 \%
$$

$93 \%$

Berdasarkan analisis deskriptif dan perhitungan maka diperoleh persentase $93 \%$ dari pengujian Functionality. Dari skor persentase yang didapat maka kualitas perangkat lunak dari sisi Functionality telah sesuai dengan atribut Functionality dan mempunyai skala yang baik.
Pengujian Security

Tabel 3 Pengujian Security

\begin{tabular}{llll}
\hline No & $\begin{array}{l}\text { Jenis Celah } \\
\text { Keamanan }\end{array}$ & $\begin{array}{l}\text { Tingkat } \\
\text { Peringat } \\
\text { an }\end{array}$ & $\begin{array}{l}\text { Juml } \\
\text { ah }\end{array}$ \\
\hline 1 & File upload & Low & 3 \\
\hline 2 & $\begin{array}{l}\text { Login page } \\
\text { password-guessing } \\
\text { attack }\end{array}$ & Low & 7 \\
\hline 3 & $\begin{array}{l}\text { Possible sensitive } \\
\text { directories }\end{array}$ & Low & 2 \\
\hline 4 & $\begin{array}{l}\text { User credentials } \\
\text { are sent in clear } \\
\text { text }\end{array}$ & Low & 2 \\
\hline 5 & $\begin{array}{l}\text { Broken links } \\
\text { informat }\end{array}$ & 0 \\
\hline 6 & $\begin{array}{l}\text { Email address } \\
\text { found }\end{array}$ & $\begin{array}{l}\text { informat } \\
\text { ional }\end{array}$ & 6 \\
\hline 7 & $\begin{array}{l}\text { Password type } \\
\text { input with } \\
\text { autocomplete } \\
\text { enabled }\end{array}$ & informat & 3 \\
& ional & \\
\hline
\end{tabular}

Analisis data pengujian security

Tabel 4 Analisa Data Pengujian Security

\begin{tabular}{lll}
\hline No & Tingkat peringatan & Jumlah \\
\hline 1 & High & - \\
\hline 2 & Medium & - \\
\hline 3 & Low & 7 \\
\hline 4 & informational & 5 \\
\hline & Total & 12 \\
\hline
\end{tabular}

Berdasarkan hasil analisis security yang diuji pada kualitas aplikasi, maka untuk sisi celah keamanan pada sistem ini bisa dikatakan telah sesuai dengan kualitas perangkat lunak yang baik.

\section{Pengujian Usability}

Tabel 5 Pengujian Usability

\begin{tabular}{|c|c|c|c|c|c|}
\hline No & Pertanyaan & $\begin{array}{l}\mathrm{T} \\
\mathrm{S}\end{array}$ & $\begin{array}{l}K \\
S\end{array}$ & S & SS \\
\hline 1 & $\begin{array}{l}\text { Secara keseluruhan } \\
\text { saya puas dengan } \\
\text { kemudahan } \\
\text { pemakaian aplikasi } \\
\text { ini }\end{array}$ & 0 & 0 & 21 & 110 \\
\hline 2 & $\begin{array}{l}\text { Sangat sederhana } \\
\text { penggunaan aplikasi } \\
\text { ini }\end{array}$ & 0 & 0 & 44 & 87 \\
\hline
\end{tabular}


Saya dapat dengan sempurna

3 menyelesaikan pekerjaan dengan aplikasi ini

\begin{tabular}{|c|c|c|c|c|c|}
\hline 4 & $\begin{array}{l}\text { Saya dapat } \\
\text { menyelesaikan } \\
\text { pekerjaan saya } \\
\text { dengan cepat } \\
\text { menggunakan } \\
\text { aplikasi ini }\end{array}$ & 0 & 0 & 43 & 88 \\
\hline 5 & $\begin{array}{l}\text { Saya dapat } \\
\text { menyelesaikan } \\
\text { pekerjaan saya } \\
\text { secara efisien } \\
\text { menggunakan } \\
\text { aplikasi ini }\end{array}$ & 0 & 12 & 59 & 60 \\
\hline 6 & $\begin{array}{l}\text { Saya merasa } \\
\text { nyaman } \\
\text { menggunakan } \\
\text { aplikasi ini }\end{array}$ & 0 & 2 & 97 & 32 \\
\hline 7 & $\begin{array}{l}\text { Sangat mudah } \\
\text { mempelajari } \\
\text { penggunaan aplikasi } \\
\text { ini }\end{array}$ & 0 & 0 & 3 & 128 \\
\hline 8 & $\begin{array}{l}\text { Pesan kesalahan } \\
\text { yang diberikan } \\
\text { aplikasi ini } \\
\text { menjelaskan dengan } \\
\text { gamblang cara } \\
\text { mengatasinya }\end{array}$ & 24 & 13 & 85 & 9 \\
\hline 9 & $\begin{array}{l}\text { Kapanpun saya } \\
\text { membuat kesalahan, } \\
\text { saya bisa } \\
\text { memperbaikinya } \\
\text { dengan cepat dan } \\
\text { mudah }\end{array}$ & 0 & 0 & $\begin{array}{r}12 \\
3\end{array}$ & 8 \\
\hline 10 & $\begin{array}{l}\text { Informasi yang } \\
\text { disediakan aplikasi } \\
\text { ini cukup jelas }\end{array}$ & 0 & 0 & 0 & 131 \\
\hline 11 & $\begin{array}{l}\text { Sangat mudah } \\
\text { mencari informasi } \\
\text { di aplikasi ini }\end{array}$ & 0 & 0 & 23 & 108 \\
\hline 12 & $\begin{array}{l}\text { Informasi yang } \\
\text { disediakan aplikasi } \\
\text { sangat mudah } \\
\text { dipahami }\end{array}$ & 0 & 0 & 0 & 131 \\
\hline 13 & $\begin{array}{l}\text { Informasi yang } \\
\text { disediakan efektif } \\
\text { membantu saya } \\
\text { mendapatkan } \\
\text { informasi }\end{array}$ & 0 & 9 & 95 & 27 \\
\hline 14 & $\begin{array}{l}\text { Pengorganisasian } \\
\text { informasi yang } \\
\text { ditampilkan aplikasi } \\
\text { sangat jelas }\end{array}$ & 0 & 0 & $\begin{array}{r}13 \\
1\end{array}$ & 0 \\
\hline 15 & $\begin{array}{l}\text { Antarmuka aplikasi } \\
\text { menyenangkan }\end{array}$ & 0 & 8 & 88 & 35 \\
\hline 16 & $\begin{array}{l}\text { Saya menyukai } \\
\text { menggunakan } \\
\text { antarmuka aplikasi } \\
\text { ini }\end{array}$ & 0 & 11 & 42 & 78 \\
\hline
\end{tabular}

Aplikasi ini

17 memiliki fungsi dan

$\begin{array}{lllll}\text { kapasitas sesuai } & 0 & 5 & 58 & 68\end{array}$

harapan saya

Secara keseluruhan,

18 saya puas dengan $\quad \begin{array}{llrrr}0 & 0 & 11 & 13\end{array}$ aplikasi ini

Apakah informasi

19 yang disediakan $\quad \begin{array}{lllll}0 & 0 & 13 & 0\end{array}$

oleh aplikasi ini

mudah dimengerti

Apakah

penggunakan menu

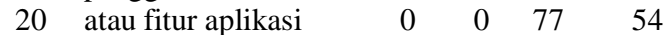

menu mudah

digunakan

\begin{tabular}{rlllrl}
\hline 21 & $\begin{array}{l}\text { Apakah aplikasi ini } \\
\text { nyaman digunakan }\end{array}$ & 0 & 0 & $\begin{array}{r}13 \\
1\end{array}$ & 0 \\
\hline 22 & $\begin{array}{l}\text { Apakah aplikasi ini } \\
\text { sesuai dengan } \\
\text { kebutuhan }\end{array}$ & 0 & 21 & 96 & 14 \\
\hline 23 & $\begin{array}{l}\text { Apakah aplikasi ini } \\
\text { dapat dengan } \\
\text { mudah dipelajari }\end{array}$ & 0 & 0 & 13 & 0 \\
\hline 24 & $\begin{array}{l}\text { Apakah aplikasi ini } \\
\text { mudah dioperasikan }\end{array}$ & 0 & 0 & 13 & 0 \\
\hline 25 & $\begin{array}{l}\text { Apakah aplikasi } \\
\text { bermanfaat bagi } \\
\text { pengguna }\end{array}$ & 0 & 0 & 11 & 13 \\
\hline $\begin{array}{l}\text { Apakah tampilan } \\
\text { menu dalam } \\
\text { aplikasi mudah } \\
\text { untuk dikenali }\end{array}$ & 0 & 0 & 34 & 97 \\
\hline $\begin{array}{l}\text { Apakah aplikasi } \\
\text { mempunyai } \\
\text { kemampuan dan } \\
\text { fungsi sesuai yang } \\
\text { diharapkan }\end{array}$ & 0 & 0 & 34 & 97 \\
\hline
\end{tabular}

\begin{tabular}{rrrrr}
\hline & & & 19 & 147 \\
Total & 24 & 81 & 56 & 6 \\
\hline
\end{tabular}

$\begin{array}{crrr}\text { TS } & 0,0067854 & \times 100 \% & 0,7 \% \\ \text { KS } & 0,0229008 & \times 100 \% & 2,2 \% \\ \text { S } & 0,553011 & \times 100 \% & 55 \% \\ \text { SS } & 0,4173028 & \times 100 \% & 42 \%\end{array}$

Berdasarkan analisis deskriptif dan perhitungan maka diperoleh persentase $42 \%$ Sangat setuju, $55 \%$ setuju, 2,2\% kurang setuju, dan $0,7 \%$ untuk respon tidak setuju. 
Analisis Pengujian Usability

Tabel 6 Analisis Pengujian Usability

\begin{tabular}{|c|c|c|}
\hline $\begin{array}{c}\text { Pertan } \\
\text { yaan }\end{array}$ & $\begin{array}{l}\text { Skor } \\
\text { Total } \\
\end{array}$ & $\begin{array}{c}\text { Skor } \\
\text { Maksimum } \\
\end{array}$ \\
\hline 1 & 503 & 524 \\
\hline 2 & 480 & 524 \\
\hline 3 & 481 & 524 \\
\hline 4 & 481 & 524 \\
\hline 5 & 417 & 524 \\
\hline 6 & 419 & 524 \\
\hline 7 & 521 & 524 \\
\hline 8 & 291 & 524 \\
\hline 9 & 401 & 524 \\
\hline 10 & 524 & 524 \\
\hline 11 & 501 & 524 \\
\hline 12 & 524 & 524 \\
\hline 13 & 393 & 524 \\
\hline 14 & 393 & 524 \\
\hline 15 & 404 & 524 \\
\hline 16 & 438 & 524 \\
\hline 17 & 446 & 524 \\
\hline 18 & 406 & 524 \\
\hline 19 & 393 & 524 \\
\hline 20 & 447 & 524 \\
\hline 21 & 393 & 524 \\
\hline 22 & 344 & 524 \\
\hline 23 & 393 & 524 \\
\hline 24 & 393 & 524 \\
\hline 25 & 406 & 524 \\
\hline 26 & 490 & 524 \\
\hline 27 & 490 & 524 \\
\hline Total & 11772 & 14148 \\
\hline
\end{tabular}

\section{$0,832061 \times 100 \% \quad 83 \%$}

Berdasarkan hasil analisa pengujian usability maka diperoleh presentase 83\%. Dari skor tersebut untuk aplikasi yang sederhana termasuk dalam kategori baik.
Pengujian efficiency

Tabel 7 Pengujian Efficiency

No Parameter Dasar Yslow Aktif

\begin{tabular}{lll}
\hline 1 & Make fewer HTTP requests & Ya \\
\hline 2 & $\begin{array}{l}\text { Compress components with } \\
\text { GZIP }\end{array}$ & Ya \\
\hline 3 & Reduce DNS lookups & Ya \\
\hline 4 & $\begin{array}{l}\text { Reduce the number of } \\
\text { DOM elements }\end{array}$ & Ya \\
\hline 5 & $\begin{array}{l}\text { Configure entity tags } \\
\text { (Etags) }\end{array}$ & Ya \\
\hline 6 & Use cookie-free domains & \\
\hline 7 & $\begin{array}{l}\text { Make JavaScript and CSS } \\
\text { external }\end{array}$ & \\
\hline
\end{tabular}

Hasil analisa Pengujian maintainability

Tabel 8 Hasil Pengujian Maintainability

Aspek Hasil yang diperoleh

\begin{tabular}{ll}
\hline Instrumentatio n & Ketika ada kesalahan \\
& yang dilakukan oleh user \\
pada saat login, maka & sistem akan mengeluarkan \\
& peringatan untuk \\
mengidentifikasi & kesalahan \\
\hline Consistency & Pada bentuk rancangan \\
& sistem mempunyai bentuk \\
& yang sama, dapat dilihat \\
& dari segi implementasi \\
& dimana tampilan halaman \\
& web dari satu halaman ke \\
& halaman lainnya memiliki \\
& kemiripan, bentuk yang \\
& serupa dan konsisten \\
\hline Hasil pengujian \\
menunjukan bahwa sistem \\
mudah untuk \\
dikembangkan
\end{tabular}

Hasil analisa pengujian portability

Tabel 9 Hasil Analisa pengujian portability

\begin{tabular}{lll} 
No & \multicolumn{1}{c}{ Browser } & Hasil \\
\hline 1 & Mozila firefox & Tidak ditemukan error \\
\hline 2 & Internet & Tidak ditemukan error \\
\hline
\end{tabular}

Jurnal Ilmiah "Technologia" 


\begin{tabular}{lll}
\hline & explorer & \\
\hline 3 & Google Chrome & Tidak ditemukan error \\
\hline
\end{tabular}

Hasil evaluasi dari 20 responden setelah implementasi dan pengujian, yaitu sebagai berikut :

Tabel 10 Kuisioner Analisa Evaluasi

\begin{tabular}{|c|c|c|}
\hline Variabel & $\begin{array}{l}\text { Jumlah } \\
\text { Respon }\end{array}$ & Presentase \\
\hline $\begin{array}{lr}\text { Sangat } & \text { Puas } \\
\text { dengan } & \text { aplikasi } \\
\text { ini? } & \end{array}$ & $\begin{array}{c}19 \\
\text { orang }\end{array}$ & $95 \%$ \\
\hline $\begin{array}{ll}\text { Sangat } & \text { setuju } \\
\text { digunakan } & \text { untuk } \\
\text { konsultasi } & \\
\text { bimbingan online }\end{array}$ & $\begin{array}{c}18 \\
\text { orang }\end{array}$ & $85 \%$ \\
\hline $\begin{array}{l}\text { Setuju untuk } \\
\text { mengurangi } \\
\text { sampah kertas }\end{array}$ & $\begin{array}{c}17 \\
\text { orang }\end{array}$ & $85 \%$ \\
\hline $\begin{array}{l}\text { Setuju } \\
\text { mengefisiensikan } \\
\text { masa bimbingan }\end{array}$ & $\begin{array}{c}18 \\
\text { orang }\end{array}$ & $85 \%$ \\
\hline $\begin{array}{l}\text { sistem } \\
\text { konvensional } \\
\text { dalam konsultasi } \\
\text { bimbingan skripsi } \\
\text { harus didampingi } \\
\text { dengan aplikasi } \\
\text { konsultasi online }\end{array}$ & $\begin{array}{c}20 \\
\text { orang }\end{array}$ & $100 \%$ \\
\hline
\end{tabular}

Berdasarkan hasil diatas rata-rata presentasenya adalah $90 \%$ setuju dan puas setelah menggunakan aplikasi tersebut

\section{KESIMPULAN}

Kesimpulan yang didapatkan setelah melakukan implementasi dan beberapa pengujiian, maka dapat dipaparkan yaitu:

1. Tahap pengujian functionality untuk analisa pengujian perangkat lunak memperoleh presentase $93 \%$ yang termasuk dalam kategori baik

2. Tahap pengujian usability hasil analisa pengujian maka diperoleh presentase $83 \%$. Dari skor tersebut untuk aplikasi yang sederhana termasuk dalam kategori baik.

3. Hasil evaluasi akhir dari penggunaan sistem mendapatkan nilai presentase

Jurnal Ilmiah “Technologia” rata-rata $90 \%$ mendapatkan respon yang bagus dari responden sehingga layak untuk digunakan sebagai aplikasi konsultasi bimbingan skripsi online.

Saran dari penelitian yang telah dilakukan adalah sebagai berikut :

1. Perlu tambahan fitur cetak untuk halaman pengesahan

2. Adanya tambahan fitur cetak data pada halaman admin

3. Perlu ditambahkan fitur video call agar bisa melakukan konsultasi secara streaming.

4. Tingkat kemanan pada sistem masih kurang

\section{REFERENSI}

1] Jovan, F. N. (2007). Panduan Praktis Membuat WEB dengan PHP utk Pemula. Mediakita.

2] KURYANTI, Sandra Jamu. Rancangan Aplikasi Pengajuan Kartu Kuning Secara Online (Studi Kasus: Dinas Tenaga Kerja Dan Transmigrasi Kabupaten Musi Rawas). SNIT 2015, 2015, 1.1: 33-37.

3] Mahalisa, G. (2018).

PERANCANGAN SISTEM

INFORMASI KAMPUS (SIK)

BERBASIS WEBSITE STUDI

KASUS KAMPUS UNISKA.

SEMINASTIKA UNIVERSITAS

MULIA BALIKPAPAN, 1(001), 101-

103.

4] Mahalisa, G., \& Syafarina, G. A. (2018). ANALISIS PERANCANGAN E-SCHEDULE PERKULIAHAN. Technologia: Jurnal Ilmiah, 9(3), 185187.

5] WIBOWO, Farian Gustarto; NUGROHO, Eko; WINARNO, Wing Wahyu. Perancangan model sistem otomatisasi pengajuan angka kredit 


$\begin{array}{llr}\begin{array}{l}\text { dengan } \\ \text { architecture }\end{array} \text { development } & \begin{array}{r}\text { togaf } \\ \text { method }\end{array} \\ \text { (studi kasus: } & \text { Badan } & \text { Pemeriksa } \\ \text { Keuangan } & \text { RI). } & \text { STUDIA } \\ \text { INFORMATIKA: } & \text { JURNAL } & \text { SISTEM } \\ \text { INFORMASI, 2013, 6.1. } & \end{array}$

6] ARIF, Saiful Nur; WANDA, Ayu Putri; MASUDI, Abdi. Aplikasi Administrasi Perpustakaan Berbasis Web SMK Swasta Brigjend Katamso Medan. Jurnal SAINTIKOM Vol, 2013, 12.1.

7] MARTIN, James. Information engineering: book II: planning and analysis. Prentice-Hall, Incorporated, 1989

8] A. P. M. A. Arif, Nur Saiful; Wanda, "Aplikasi Administrasi Perpustakaan Berbasis Web Smk Swasta Brigjend Katamso Medan," J. Ilm. Saintikom, 2013

9] Kasiman, P. (2009). Aplikasi Web dengan PHP dan MySQL. Yogyakarta: ANDI. 